\title{
A EXTENSÃO UNIVERSITÁRIA NA EFETIVAÇÃO DOS DIREITOS FUNDAMENTAIS COLETIVOS
}

\author{
Alexandre Missaggia Vacari ${ }^{1}$ \\ Cecília Amaral do amaral ${ }^{2}$ \\ Eduardo Jesus Sanches ${ }^{3}$
}

\begin{abstract}
RESUMO: Os direitos e garantias fundamentais, que hoje são pedra base dos diversos Estados Democráticos de Direito, apresentam-se como conquistas sociais, adquiridas através de árduo esforço. Todavia, muitas das suas previsões, principalmente aquelas sobre direitos coletivos, não passam de conquistas formais, devido a sua ínfima aplicação. Na tentativa de alterar essa conjuntura, a universidade pode, através de projetos de extensão, influir na concretização de tais Direitos Coletivos, fazer valer seu conhecimento em benefício da sociedade. Para tanto o "Projeto de Direitos Coletivos" propõe, através deste artigo, um fortalecimento deste campo jurídico, através do estudo dos direitos e garantias fundamentais, dos instrumentos para concretização da tutela coletiva e do conseqüente auxílio na implementação dos mesmos.
\end{abstract}

PALAVRAS-CHAVES: Direitos fundamentais - Direitos Coletivos - Extensão Universitária.

\section{The universitarian extension in the accomplishment of the collective fundamental rights}

ABSTRACT: The fundamental rights and warranties which are the base of the several Democratic States of Right nowadays, arise as social conquests, acquired through hard effort. However, a lot of their previsions, principally those about collective rights, are simply formal conquests, due to their insignificant application. Trying to alter this conjuncture, the university can, through extension projects, influence in the realization of such collective rights, stake its knowledge in benefit of the society. Therefore, the "Project of Collective Rights" proposes, through this article, a strengthening of this juridical field, through the study of the fundamental rights and warranties, through the instruments for the realization of the collective tutelage and through the consequent support in the implementation of these rights.

KEY-WORDS: Fundamental Right - Collective Rights - Universitarian Extension.

\section{INTRODUÇÃO}

O presente artigo tem por objetivo analisar os direitos fundamentais coletivos, desde sua história e conceituação até os instrumentos processuais capazes de implementá-los, e, por fim, propor meios para que a universidade, através da extensão, participe de tal efetivação. Para isso, num primeiro momento, se fará uma pequena abordagem dos direitos e das garantias fundamentais, haja vista que os direitos coletivos são fundamentais em sua origem e essência. Num segundo momento, tais direitos, mais

\footnotetext{
${ }^{1}$ Acadêmico do 10o Semestre do Curso de Direito Diurno da UFSM.

${ }^{2}$ Acadêmica do 9o Semestre do Curso de Direito Diurno da UFSM.
}

ISSN - 1981-3694

(C) 2007. Departamento de Direito da UFSM. Todos os direitos reservados. 
propriamente denominados transindividuais, serão abordados de forma mais específica, de modo a permitir uma análise na evolução legislativa brasileira que dispõe sobre a tutela jurisdicional desses direitos - através dos chamados instrumentos processuais coletivos - para, posteriormente, serem descritos, alguns destes instrumentos. Estes instrumentos possibilitarão, na terceira parte do artigo, a construção de uma proposta onde haja o efetivo envolvimento da universidade na concretização dos direitos de massa. Tal proposta apresentada constitui o objetivo do embrionário "Projeto de Direitos Coletivos", que pretende consolidar-se na Universidade Federal de Santa Maria.

\section{DOS DIREITOS E DAS GARANTIAS FUNDAMENTAIS}

No que concerne à análise da origem e da evolução dos direitos fundamentais, far-se-ão, apenas, algumas considerações acerca da evolução histórica e conceitual destes direitos por não ser objetivo específico do presente trabalho.

As primeiras manifestações escritas com conteúdos essencialmente de resistência do homem frente ao poder instituído dos governantes datam de muitos anos, sendo encontradas na filosofia da Grécia antiga, no direito romano, na idade média, no pensamento de Buda e de Santo Thomaz de Aquino.

Porém, é com o surgimento do Estado Moderno, ou, mais especificamente, na iminência e pós-alvoroço da revolução francesa e processo de independência das colônias inglesas na América do Norte e, com pequeno conteúdo, na "Magna Carta Inglesa", que surgem e ganham relevo material, as declarações de direitos.

Por conseguinte, pode-se dizer, tranqüilamente, que a idéia de direitos fundamentais está estritamente ligada à de constitucionalização e de Estado de Direito, ou seja, somente a partir do fenômeno dos diplomas escritos, baseados nos ideais de liberdade, de igualdade, de fraternidade, de legalidade e de dignidade da pessoa humana, oriundos do final do séc. XVIII e do decorrer dos séculos XIX e XX, é que se pode falar em surgimento de uma verdadeira classe de direitos e garantias fundamentais para os cidadãos, frente ao, até então, poder ilimitado e tirano dos governantes.

\footnotetext{
${ }^{3}$ Acadêmica do 9o Semestre do Curso de Direito Diurno da UFSM.
} 
Para tratar da caracterização e conceituação dos direitos fundamentais, Canotilho (1993) ensina que uma teoria dos direitos fundamentais insinua uma aproximação com uma categoria dogmática a partir de seus três sentidos:

a) analítico; b) empírico; e c) normativo, sendo que por direitos fundamentais entendem-se os direitos dos homens, jurídico-institucionalmente garantidos e limitados espacio-temporalmente, objetivamente vigentes numa ordem jurídica concreta. Logo encobre-se numa estrutura complexa de normas, garantidoras de direitos subjetivos e impositivos deveres objetivos, cumprindo um função de direitos de defesa dos cidadãos sob uma dupla perspectiva: a) constituem normas de competência negativa para os poderes públicos, proibindo fundamentalmente as ingerências destes na esfera jurídica individual; b) implicam, num plano jurídico-subjetivo, o poder de exercer positivamente direitos fundamentais (liberdade positiva) e de exigir omissões dos poderes públicos, de forma a evitar agressões lesivas por parte dos mesmos (liberdade negativa). (CANOTILHO, 1993, p. 496).

Os direitos fundamentais, então, são considerados como direitos subjetivos, mas não apenas de natureza negativa, ou seja, de barreira imposta à atuação estatal, mas sim posições jurídicas ocupadas pelo indivíduo de fazer valer sua pretensão frente ao Estado (revelam-se aqui os direitos a ações positivas contrapondo-se aos direitos de defesa, passando a exigir-se do Estado, como titular de direitos subjetivos, proteção, organização, procedimento e prestação lato sensu - direitos sociais fundamentais).

Cumpre destacar as palavras de Bobbio (1992, p.19), para quem “a verdadeira concepção de direitos fundamentais teria por pressuposto a questão histórica, pois os direitos do homem constituem uma classe variável, cujo elenco modifica-se continuamente com a alteração das condições históricas determinantes, fator essencial para derrubar a idéia de direitos fundamentais por natureza".

Assim, a definição de quais são os direitos fundamentais não é estática, mas dinâmica, é o momento histórico de cada sociedade que os determina. Considerando isso, cumpre destacar que a tradicional classificação utilizada por Bobbio (1992), referente às 3 gerações dos direitos fundamentais, já se encontra superada por uma discussão que diz com a busca da efetivação destes direitos.

O que importa, num contexto atual, é situar os momentos históricos por quais passaram as afirmações dos chamados direitos fundamentais dos Estados para, acima da busca de uma conceituação, ou mesmo classificação, exata, estar-se preparado a buscar, na práxis, a real efetivação dos mesmos. 


\subsection{Direitos fundamentais na Constituição Brasileira}

Alguns pontos importantes no que tange aos direitos fundamentais previstos em nosso texto constitucional devem ser enfrentados, antes de se passar, especificamente, à análise do Direito Coletivo Brasileiro.

Merece revelo, assim, o reconhecimento unânime da doutrina no que se refere à posição privilegiada que o nosso constituinte conferiu aos direitos fundamentais, em virtude da posição em que estão exemplificativamente expostos nos primeiros artigos de nossa Constituição. Isso significa que, dentro de uma constituição analógica e dirigente, como a nossa, os direitos fundamentais constituem um alicerce orientador de toda a Hermenêutica constitucional e infraconstitucional.

Importante, também, mencionar outras características, tais como as que remetem a nota da aplicabilidade imediata dos direitos fundamentais, esculpida no art. $5^{\circ} \S 1^{\circ}$ da $\mathrm{CF} / 88$, bem como a proteção especial destinada pelo constituinte ao conjunto de direitos fundamentais, pelo fato de terem sido guindados à condição de limites materiais à reforma constitucional, as chamadas "cláusulas pétreas", como consignado no art. 60, $\S 4^{\circ}$, IV de nossa lei fundamental.

Feita esta breve abordagem acerca dos direitos fundamentais, passar-se-á à análise da ascensão dos interesses metaindividuais, destacando a importância da tutela jurisdicional dos direitos coletivos. Apresentar-se-á, outrossim, alguns instrumentos para a defesa destes direitos.

\section{PROTEÇÃO DOS DIREITOS FUNDAMENTAIS NUMA PERSPECTIVA COLETIVA}

Nos dias atuais, caracterizado pelo desenfreado desenvolvimento tecnológico, pelo consumismo exacerbado, bem como pela individualização das relações humanas, é necessário, e cada vez mais tem sido difundido, o debate sobre a ascensão dos interesses transindividuais.

Convém, no entanto, situar, brevemente, os direitos coletivos no contexto que fora acima abordado, antes de adentrarmos no histórico legislativo brasileiro que buscou positivar tais direitos e defini-los.

Como foi possível constatar, os direitos fundamentais transmitem-nos a idéia de imprescindibilidade, característica essa, hoje, inerente aos interesses transindividuais. Essa qualidade de "fundamentais" se agrega aos direitos coletivos desde que a 
passagem do Estado Liberal para um Estado Social trouxe à tona os chamados direitos de $2^{\circ}$ dimensão, caracterizados por Bonavides (1997) como direitos sociais e coletivos, ou de coletividade.

Cite-se, ainda, que para o referido doutrinador, surgem, no final do século XX, os direitos de terceira dimensão, também conhecidos como os direitos de fraternidade, para, então, surgirem os direitos de quarta dimensão, numa concepção de oposição à globalização neoliberal, devendo a quarta geração representar a globalização dos direitos fundamentais através da sua universalização. Segundo Bonavides (1997) o direito à democracia, o direito à informação e o direito ao pluralismo são direitos de quarta geração.

\subsection{Ascensão dos interesses transindividuais}

É neste contexto, então, que se deve analisar a evolução da legislação brasileira no que se refere aos interesses transindividuais. $\mathrm{Na}$ verdade, a própria denominação "interesses transindividuais" foi trazida por uma das principais leis que regem tais interesses, que é a Lei 8.078/90, ou seja, o denominado Código de Defesa do Consumidor (CDC).

De acordo com a referida legislação, os interesses transindividuais abrangem os interesses difusos, os interesses coletivos e, ainda, os interesses individuais homogêneos. Os difusos são aqueles interesses ou direitos transindividuais, de natureza indivisível, de que sejam titulares pessoas indeterminadas e ligadas por circunstâncias de fato, como é o caso do meio ambiente.

Os direitos coletivos, por sua vez, podem ser vistos em sentido lato, como bem nos demonstra o doutrinador Hugo Nigro Mazzilli (2002), sendo esta larga concepção trazida pela própria Constituição Federal, em seu art. 129, III. No entanto, o significado que convém apresentarmos refere-se aos direitos coletivos em sentido estrito, aqueles que estão ao lado dos direitos difusos e dos individuais homogêneos, e que, para este doutrinador, formariam os direitos coletivos lato sensu. Coletivos, em sentido estrito, então, são os interesses indivisíveis de um grupo determinado ou determinável de pessoas, reunidas por uma relação jurídica básica comum.

Por fim, são direitos individuais homogêneos aqueles de grupo, categoria ou classe de pessoas determinadas ou determináveis que compartilhem prejuízos divisíveis, de origem comum, normalmente oriundos das mesmas circunstâncias de fato. 
Cumpre ressaltar, no entanto, que o surgimento da tutela dos interesses difusos e coletivos se deu com a Lei 7.347/85, conhecida como a Lei da Ação Civil Pública (LACP) e reconhecida como a lei que revolucionou o direito processual brasileiro. Isso porque não se pode falar em Direito Processual Coletivo antes da entrada em vigor da referida lei.

Desta forma, pode-se considerar que a LACP, o CDC e a própria Constituição Federal de 1988, conhecida como "Constituição Cidadã", representam hoje um Microssistema de Tutela Jurisdicional Coletiva, imprescindíveis à defesa dos direitos coletivos, uma vez que a natureza individualista do Código Processual Civil não é adequada para tal.

Neste aspecto, antes de se adentrar em alguns dos instrumentos de jurisdição coletiva mais especificamente, cumpre ressaltar a existência do Anteprojeto do Código Brasileiro de Processos Coletivos, cujos trabalhos de elaboração foram coordenados pela professora Ada Pellegrini Grinover.

Nas palavras da própria doutrinadora (2007), constante na exposição de motivos do referido Anteprojeto:

(...) o texto ora apresentado representa um esforço coletivo, sério e equilibrado, no sentido de reunir, sistematizar e melhorar as regras brasileiras sobre processos coletivos, hoje existentes em leis esparsas, às vezes inconciliáveis entre si, harmonizando-as e conferindo-lhes tratamento consentâneo com a relevância jurídica, social e política dos interesses e direitos transindividuais e individuais homogêneos. Tudo com o objetivo de tornar sua aplicação mais clara e correta, de superar obstáculos e entraves que têm surgido na prática legislativa e judiciária e de inovar na técnica processual, de modo a extrair a maior efetividade possível de importantes instrumentos constitucionais de direito processual.

Antes mesmo de se tornar Projeto de Lei, o Código Brasileiro de Processos Coletivos vem sofrendo algumas críticas por parte de algumas promotorias de justiça, como é o caso do Ministério Público de Minas Gerais, que através da Resolução no 75/2005 criou uma Comissão para debater e avaliar o referido Anteprojeto.

O relatório, elaborado por Gregório Assagra (2005) em decorrência dos estudos realizados por esta Comissão, apontou algumas críticas pontuais acerca de determinados artigos, destacando-se, principalmente, a crítica referente ao momento, que não é adequado para a codificação do direito processual coletivo brasileiro. Isto porque entende que o Microssistema de Tutela Jurisdicional Coletiva (LACP + CDC + 
$\mathrm{CF}$ ) possui somente quinze anos e que apesar de já ter produzido muitos frutos, ainda resta muito a ser produzido e desenvolvido para a consagração de um código realmente inovador no País.

Além disso, destacou a crise política pela qual está passando nosso Congresso Nacional e que tais riscos, associados à falta de um verdadeiro e aberto debate sobre o tema, poderão gerar verdadeiros retrocessos.

É justamente este ponto que se quer destacar do referido relatório, ou seja, a preocupação em manter a evolução do processo coletivo brasileiro, que visa tutelar os supramencionados direitos transindividuais. Não se pode deixar de referir, também, os diversos pontos positivos que foram apontados em relação ao Anteprojeto, tais como os princípios que devem reger a tutela jurisdicional coletiva, dos quais se destacam: a tutela coletiva adequada; a cooperação dos órgãos públicos na produção da prova; a flexibilização da técnica processual; a intervenção do Ministério Público; a continuidade da ação coletiva; a obrigatoriedade do cumprimento e da execução da sentença; bem como a extensão subjetiva da coisa julgada.

Desta forma, confirma-se a importância que vem sendo dada à tutela dos interesses coletivos, bem como a imprescindibilidade de normas processuais próprias para a defesa desses direitos, uma vez que o atual modelo individualista do Código de Processo Civil não é capaz de fazê-lo.

\subsection{Análise dos instrumentos aptos para defesa dos direitos coletivos}

Analisada a ascensão dos direitos coletivos (em sentido lato), e exposta sinteticamente a evolução da legislação brasileira sobre a tutela destes direitos - o que se tem denominado processo coletivo brasileiro - cumpre analisar, brevemente, alguns dos atuais instrumentos que servem a esta proteção.

Pode-se iniciar destacando a antiguíssima Lei 4.717 de 1965, conhecida como Lei da Ação Popular e que foi trazida pela primeira vez pela nossa Constituição Federal de 1934, tendo sido, outrossim, alterada pela atual Constituição Federal. A Ação Popular tem destacada importância pelo fato de permitir ao cidadão brasileiro o comparecimento em juízo na defesa de interesse comum.

A Ação Popular, remédio constitucional pelo qual o cidadão fica investido de legitimidade para o exercício de um poder da natureza essencialmente política, constitui instrumento fundamental do Estado Democrático de Direito, pois representa a manifestação direta da soberania popular. O autor Gregório Assagra de Almeida (2003, 
p. 439) chega a referir, inclusive, que "a ação popular é a mais legítima das ações coletivas, pois o seu legitimado ativo é também titular do direito difuso tutelável via ação popular".

Cite-se, ainda, os demais instrumentos constitucionais do Direito Processual Coletivo Brasileiro, tais como: o mandado de segurança coletivo, o mandado de injunção, o dissídio coletivo, a ação de impugnação de mandato eletivo, a ação direta interventiva, e, ainda, a já citada Ação Civil Pública.

Tal ação, como já referido anteriormente, foi regulamentada pela Lei 7.347/85, que enunciou a tutela de bens e direitos de valor artístico, estético, histórico, turístico e paisagístico, viabilizando, assim, a tutela desta categoria de bens e direitos. Foi a precursora da tutela jurisdicional dos direitos coletivos, e ao lado do Código de Defesa do Consumidor, representa hoje a mais importante lei que trata do processo coletivo.

Por sua vez, a Lei 8.078/90, que deu origem ao CDC, veio para atender ao disposto no art. $5^{\circ}, \mathrm{XXXII}$, da $\mathrm{CF} / 88$, tendo avançado sobremaneira rumo à efetividade da tutela dos direitos e interesses coletivos no Brasil. É concebida, pelos doutrinadores, como uma lei bastante avançada, tanto no plano material como no aspecto processual, onde reserva uma parte, especialmente, às ações de tutela de direitos ou interesses coletivos lato sensu.

Não cabe, no presente artigo, analisar cada evolução trazida, principalmente na parte processual, pelo $\mathrm{CDC}$; mas sim referir e destacar que tal diploma legal foi o responsável pela definição da terminologia dos direitos transindividuais - que abrange os direitos difusos, coletivos e individuais homogêneos - e também, que, nas palavras de Assagra (2003, p. 361) "tem importância capital para a proteção dos direitos ou interesses massificados, e suas disposições processuais constituem normas de sobredireito processual coletivo comum".

Pode-se discorrer sobre outros diplomas infraconstitucionais de tutela jurisdicional coletiva do direito brasileiro, no entanto, serão apenas citados, eis que o objetivo maior do presente artigo se baseia na demonstração da importância dos direitos coletivos, bem como na propositura de maneiras que busquem dar maior efetividade à sua proteção.

Cite-se, portanto, a Consolidação das Leis Trabalhistas, onde se destaca a figura do dissídio coletivo; a Lei de Improbidade Administrativa (Lei 8.429/92); o Estatuto da Criança e do Adolescente (Lei 8.069/90); a Lei Protetiva da Pessoa Portadora de Deficiência (Lei 7.853/89), o estatuto do Idoso (Lei 10.741/2003), e, ainda, as ações 
que tem por fim exercer o controle de constitucionalidade das normas (ADIn, ADCon e ADPF), mas que estão previstas, por sua vez, na própria Constituição Federal.

A evolução, portanto, de nossa legislação pátria acerca da tutela jurisdicional dos direitos coletivos possibilita a responsável aplicação dos instrumentos acima referidos e, consequentemente, uma maior efetivação dos direitos coletivos.

Contudo, em que pese a necessidade de algumas mudanças e aprimoramentos na legislação referente a este novo ramo do direito processual, que é o direito processual coletivo, é necessário desde já estar-se apto a aplicar os instrumentos então vigentes, de forma a contribuir cada vez mais para a concretização da tutela dos direitos de massa.

A partir de então, apresentar-se-á uma proposta prática, a ser seguida pelo Projeto de Direitos Coletivos - que se pretende consolidar na Universidade Federal de Santa Maria -, de buscar, através de uma determinada metodologia, a atuação da universidade na efetiva proteção dos referidos direitos.

\section{A EXTENSÃO E OS DIREITOS COLETIVOS}

Os direitos coletivos, por serem direitos de massa, são os mais aptos a afetar, de maneira ampla, as relações sociais. Com isso, são, também, os mais aptos a concretizar a justiça, considerando esta como sendo a efetiva fruição dos direitos e garantias positivados, que, apesar de serem o mínimo, não estão a ser respeitados.

Todavia, assim como muitos direitos, os próprios instrumentos para sua efetivação estão, ainda, somente no campo da previsão, devido a fatores como a inércia dos seus legitimados ou o desconhecimento por parte destes. Sendo assim, mostra-se imperioso o fortalecimento dos instrumentos coletivos para que, através desses meios, se chegue à justiça.

O necessário é passarmos para a concretização dos Direitos Coletivos, ou seja, deixarmos de nos contentar com sua mera previsão. Nas palavras de Benjamim (1993, apud ALMEIDA, 2003):

A relação entre regulação e implementação parece evidente. Sinteticamente a regulação consiste na criação de um aparato legal, enquanto a implementação se apresenta como aplicação, caso a caso, de tal aparato. Ou seja, a regulamentação se mostra como um ente mais abstrato ou distante, enquanto a implementação ganha vida no dia a dia, como um ente concreto mais 
preocupado com o os fatos do que com as hipóteses. (BENJAMIM,1993, p.164 apud ALMEIDA, 2003, p.269)

$\mathrm{Na}$ busca de tal implementação a universidade, como produtora de conhecimento, deve se colocar como participante ativa desse movimento, isto por dois motivos. Primeiro para respeitar uma função que se desprende naturalmente de sua atividade, que é a função distributiva do conhecimento. O outro está relacionado ao aperfeiçoamento da própria instituição que necessita de uma constante "reciclagem" em seus conteúdos e métodos de ensino. Para tanto, um constante contato com a sociedade (que por fim é o campo de aplicação das diversas ciências) se faz indispensável.

São diversas, se não todas, as ciências que podem afetar esse processo, mas aqui trataremos especificamente do caso da participação das ciências jurídicas em tal transformação.

Para alcançar o status de participante ativo do processo de fortalecimento dos instrumentos processuais coletivos, a melhor postura a ser tomada, ao nosso ver, é a "extensionista", ou seja, através de projetos de extensão aproximar o conhecimento da academia dos que estão carentes dele, e com eles formar uma frente de luta pelos direitos coletivos.

Constitui esta a proposta central do recém-criado "Projeto de Direitos Coletivos".

\subsection{Métodos extensionistas para a efetivação dos Direitos Coletivos}

$\mathrm{Na}$ tentativa de auxiliar na implementação dos Direitos Coletivos deve-se atentar para a necessidade de duas frentes de trabalho, uma direcionada para "dentro" e outra para "fora" da universidade.

Apesar de viver do saber, a universidade possui suas carências no que diz respeito ao conhecimento de certas áreas e de certas atitudes. A esfera coletiva do direito e a prática extensionista são exemplos claros das carências referidas, e para que seja feito um trabalho eficaz devem ser superadas. Para tal, o Núcleo se propõe a ampliar a presença do tema "Direitos Coletivos na universidade", além de buscar despertar o espírito extensionista tanto nos acadêmicos como nos professores. Tais objetivos seriam alcançados através de palestras e oficinas organizadas pelo Núcleo e voltadas para acadêmicos e professores, de forma a familiarizar o mundo acadêmico com esta área tão importante do Direito. 
O Direito como decifrador dos meandros jurídicos, é conhecimento necessário, pois é a garantia de acesso adequado as instâncias judiciais a quem, por fim, compete garantir a eficácia dos direitos.

Mas como toda ciência o Direito vive sob uma névoa de misticismo e desconhecimento. As pessoas, principalmente, as carentes, não se vêem como possíveis defensoras dos seus direitos, elas interiorizaram que a prestação dos serviços públicos (aqui se entenda como os diversos deveres dos poderes constituídos) é quase que um "favor" que os detentores de poder prestam.

Por outro lado, a maior parte dos legitimados a pleitear judicialmente os direitos coletivos desconhecem os meios e a forma de fazê-lo, tornando quase que morta às previsões dos ditos instrumentos.

Para alterar tal conjuntura, o Núcleo buscará espalhar o conhecimento sobre estes instrumentos que garantem a tutela coletiva, e isto se fará de formas diferentes para cada instrumento, através da metodologia descrita a seguir.

É bom ressaltar que os instrumentos coletivos não se restringem aos que aqui serão tratados, apenas refletem os que inicialmente serão objeto de trabalho do Núcleo, sendo esses a Ação Civil Pública, a Ação Popular e o Mandado de Segurança Coletivo.

Como já dito, espalhar o conhecimento é fundamental para o êxito da proposta descrita neste trabalho, assim o primeiro passo é conhecer as pessoas, físicas ou jurídicas, com legitimidade para pleitear em juízo os ditos Direitos Coletivos. Importante verificar que cada instrumento possui diferentes legitimados, assim como tutelam diferentes objetos. Através dessa premissa se retira o segundo passo, ou seja, esclarecer aos legitimados quais direitos eles estão aptos a defender ou requerer.

No caso da Ação Civil Pública e no Mandado de Segurança Coletivo, nosso trabalho vai ser levar ao conhecimento das associações, que se enquadrem no rol dos legitimados, os motivos que podem levá-los a propor uma Ação Civil Pública, isto através de palestras, seminários e outras atividades com a direção e com os associados.

Já no caso da Ação Popular, devido ser de legitimidade irrestrita, ou seja, qualquer cidadão é parte legitima para propor tal ação, seu conhecimento deve ser o mais disseminado possível, para tal, as atividades do Núcleo se darão junto às comunidades, usando-se de canal de acesso as associações comunitárias que detém o importante papel de organização das localidades.

Concomitante ao contato feito com os legitimados a propor as ações percebemos que se faz necessário, para fim de alcançar o objetivo de concretização dos direitos 
coletivos e impedir que a população continue refém de sua falta de conhecimento, um contato com a base da população, entenda-se os jovens. Neste caso o trabalho será feito com as escolas e de forma menos expositiva, utilizando-se de oficinas e dinâmicas para facilitar o primeiro contato com o Direito.

Por fim, as atividades do grupo não se exaurem na disseminação do conhecimento sobre os direitos coletivos e os instrumentos para efetivá-los, o que, por si só, já é um objetivo audacioso, mas também se posta a auxiliar as possíveis ações propostas pelos legitimados referidos neste trabalho. Sendo assim, o Núcleo, também, se apresenta como um projeto de assessoria de Direitos Coletivos, participando diretamente, quando requisitado nas possíveis ações propostas.

Portanto, são muitas as áreas que devem ser afetadas para que da regulação passemos para a implementação, e essa é uma luta de todos os dias. Luta que o Núcleo resolveu, com as armas da vontade e do conhecimento, se engajar.

O que se quer, é utilizar-se da Universidade para concretizar direitos, bem como utilizar-se da comunidade para ampliar conhecimentos, realizando, assim, um ciclo de benefícios onde os agentes ajudam-se mutuamente e, como resultado, auxiliam a sociedade na consolidação do Estado democrático de Direito.

\section{CONSIDERAÇÕES FINAIS}

Ficou claro, portanto, a amplitude e a força deste novo campo da ciência jurídica, que é o Direito Processual Coletivo, cuja finalidade é assegurar a efetivação dos direitos transindividuais, também chamados direitos coletivos (em sentido lato). É um ramo que cresce e tende a crescer ainda mais, sendo que a nossa obrigação, desde já, consiste em buscar a implementação das normas já positivadas e atualmente vigentes.

Para isso, faz-se necessária a disseminação do conhecimento sobre os instrumentos processuais que garantem a eficácia dos direitos coletivos, de forma a possibilitar a efetiva aplicação dos mesmos.

Neste contexto, a universidade não pode se por à parte desta evolução, pelo contrário, deve postar-se como agente ativo na consolidação dos direitos coletivos. A utilização, pela sociedade, do conhecimento produzido dentro da universidade, no caso o conhecimento jurídico, preenche o vácuo da falta do "saber" técnico por parte dos legitimados às ações coletivas, ao mesmo tempo que aprimora a formação dos estudantes no instante que os transporta do mundo ficto para o real. 
Por essa razão surgiu o Projeto de Direitos Coletivos, objetivando, através da extensão universitária, espalhar o conhecimento sobre os instrumentos processuais coletivos e participar ativamente na concretização destes "novos direitos".

\section{REFERÊNCIAS BIBLIOGRÁFICAS}

ANTEPROJETO DE CÓDIGO BRASILEIRO DE PROCESSOS COLETIVOS. Disponível em http://www.direitoprocessual.org.br. Acesso em: 02 abr. 2007.

ALEXY, Robert. Teoria de los derechos fundamentales. Madri: Centro de Estudos Constitucionales, 1997.

ALMEIDA, Gregório Assagra de. Direito processual Coletivo Brasileiro: um novo ramo do direito processual. São Paulo; Saraiva, 2003.

ALMEIDA, Gregório Assagra de. Análise crítica de Anteprojeto de Código Brasileiro de Processos Coletivos. Artigo disponível em http://www.direito.ufmg.br/neda/arquivos/criticas_mp.doc. Acesso em 02 abr. 2007.

ANDRADE, José Carlos Vieira de. Os direitos fundamentais na Constituição Portuguesa de 1976. Coimbra: Almedita, 1987.

BOBBIO, Norberto. A era dos direitos. Trad. por Carlos Nelson Coutinho. Rio de Janeiro: Campos, 1992.

BONAVIDES, Paulo. Curso de Direito Constitucional. $7^{\text {a }}$ ed. São Paulo: editora Malheiros, 1997.

CAnOtilho, J. J. Gomes. Direito Constitucional e Teoria da Constituição. Coimbra: Almedita, 1998.

MAZZILLI, Hugo Nigro. A defesa dos interesses difusos em juízo: meio ambiente, consumidor, patrimônio cultural, patrimônio público e outros interesses. $15^{\mathrm{a}} \mathrm{ed}$. rev., ampl. e atual. São Paulo: Saraiva, 2002. 
SARLET, Ingo Wolgang. A eficácia dos direitos fundamentais. $4^{\mathrm{a}}$ ed. rev., atual e ampl. Porto Alegre: Livraria do Advogado Editora, 2004. 